\title{
Catalytic activity of polymer-bound Ru(III)-EDTA complex
}

\author{
MAHESH K DALAL and R N RAM* \\ Chemistry Department, Faculty of Science, M S University of Baroda, Baroda 390 002, India
}

MS received 17 May 2000; revised 13 February 2001

\begin{abstract}
Chloromethylated styrene-divinylbenzene copolymer was chemically modified with ethylenediaminetetraacetic acid ligand. Catalytically active polymer containing Ru(III) moieties were synthesized from this polymeric ligand. They were characterized using FTIR, UV-vis, SEM, ESR and TGA. Other physico-chemical properties such as bulk density, surface area, moisture content and swelling behaviour in different solvents were also studied. The polymer bound complex was used to study hydrogenation of 1-hexene to $n$-hexane under mild conditions. Influence of [1-hexene], [catalyst], temperature and nature of the solvent on the rate of the reaction was investigated. A rate expression is proposed based on the observed initial rate data. Recycling efficiency of the catalyst has also been studied.
\end{abstract}

Keywords. Catalytic hydrogenation; energy of activation for catalytic hydrogenation; kinetics of hydrogenation of 1-hexene; polymer-bound catalyst; polymer-bound Ru(III)-EDTA complex; study of life cycle of polymer-bound catalyst.

\section{Introduction}

Hydrogenation is an important application of catalysis in organic synthesis (Augustine 1997). Soluble homogeneous catalysts offer high selectivity at mild operating conditions but are not enviro-economical. On the other hand solid heterogeneous catalysts lack high activity and selectivity. Strong interest in synthesizing highly reactive and selective catalysts that can be easily separated from reaction system after completion of a reaction led to the concept of heterogenizing a homogeneous catalyst by supporting it on an insoluble support (Hartley 1985). Cross-linked polymers with specific properties are widely used as catalyst supports as they are inert, non-toxic, nonvolatile and often recyclable (Schlick et al 1996). It can induce specific control over catalytic and complexing ability of the ligand (Iwasawa 1985). Moreover, the amount of metal present on the surface of such catalysts is very small which is of economic significance in case of expensive metals as $\mathrm{Ru}$ and $\mathrm{Pd}$. Thus, polymer supported catalysts have generated a lot of interest in research. We have earlier reported catalytic activity of various metal ions such as $\mathrm{Rh}(\mathrm{I}), \mathrm{Ru}(\mathrm{III})$ and $\mathrm{Pd}(\mathrm{II})$ anchored to different cross-linked polymers using amines as chelating ligands (Gokak et al 1988; John et al 1997,1999). It could be interesting to use a ligand with $\mathrm{N}$ and $\mathrm{O}$ as donor groups. In the present work, we report synthesis of a $\mathrm{Ru}$ (III)-EDTA complex catalyst on the surface of styrene-divinylbenzene copolymer and investigate the cata-

\footnotetext{
*Author for correspondence
}

lytic activity of this catalyst for the hydrogenation of 1-hexene.

\section{Experimental}

\subsection{Materials and methods}

Chloromethylated styrene-divinylbenzene copolymer (CM-800), obtained from Ion Exchange (India) Ltd., Mumbai was treated with sodium iodide in order to enhance activity of the polymer. It was purified till the complete removal of iodide by soxhlet extraction using an ethanol-benzene $(1: 1)$ mixture and dried at $70^{\circ} \mathrm{C}$ for at least $10 \mathrm{~h}$. Dioxane, methanol and 1-hexene were distilled before use. $\mathrm{RuCl}_{3} \cdot 3 \mathrm{H}_{2} \mathrm{O}$ (Lobachemie, Mumbai) was used as received. Elemental analyses were carried out using a Coleman analyzer unit. UV-visible reflectance spectra of solid samples were recorded on a Beckmann IR-4220. ESR spectra were scanned on a Bruker ESP-300 K band spectrometer using a $100 \mathrm{kHz}$ field modulation on powdered samples at $298 \mathrm{~K}$ in $\mathrm{N}_{2}$ atmosphere. Surface area was determined using a Carlo-Erba strumentzione-1900 and TGA on a Shimadzu DT-30. Scanning electron micrographs were recorded on a Jeol SJM T-300. Swelling studies of the catalysts were carried out using polar and non-polar solvents at a constant temperature. The detailed procedure for swelling studies has been described earlier (Gokak et al 1988).

\subsection{Synthesis of catalyst}

The catalyst was synthesized as follows: $10 \mathrm{~g}$ of the polymer was kept in $500 \mathrm{ml}$ of $1: 1$ mixture of water and 
dioxane. $0 \cdot 25 \mathrm{~g}$ of EDTA was also dissolved separately in $1: 1$ mixture of water and dioxane. It was poured slowly in the above solution $(\sim 5-6 \mathrm{~h})$ and kept with a slow and constant shaking $\left(\sim 80^{\circ} \mathrm{C}\right)$ for at least seven days. The beads so prepared were washed with aqueous dioxane, deionized water and dried at $70^{\circ} \mathrm{C}$ for $10 \mathrm{~h}$. Finally the beads were purified with ethanol using soxhlet extraction and dried at $80^{\circ} \mathrm{C}$ for complete dryness. This polymeric ligand was then treated with ethanolic $\mathrm{RuCl}_{3} \cdot 3 \mathrm{H}_{2} \mathrm{O}$ $(0.3 \% \mathrm{w} / \mathrm{v})$ at room temperature for seven days to prepare the title catalyst. A change in colour of the polymer beads from light yellow to dark green was indicative of the loading of the $\mathrm{Ru}(\mathrm{III})$ on the surface of the polymer. It was then finally washed with ethanol and dried in vacuum at $70^{\circ} \mathrm{C}$. $\mathrm{Ru}$ content was estimated by spectrophotometric method using nitroso-R salt as a complexation material (Singh et al 1976). The synthesized catalyst was named as catalyst $\mathrm{H}=8 \mathrm{PRu}(\mathrm{III})-\mathrm{EDTA}$. A schematic representation of synthesis is depicted below where $P$ is copolymer of styrene-divinylbenzene and I is catalyst $\mathrm{H}$.

\subsection{Kinetics of hydrogenation}

The kinetics of hydrogenation of 1-hexene was studied at atmospheric pressure by measuring hydrogen uptake using a glass manometric apparatus. The detailed procedure and experimental set up are described elsewhere (Gokak et al

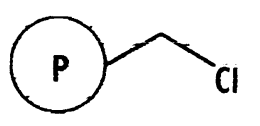

$$
\mid \begin{aligned}
& \text { EDTA } \\
& \text { Water : Dioxan (1:1) } \\
& \text { R.T. }
\end{aligned}
$$

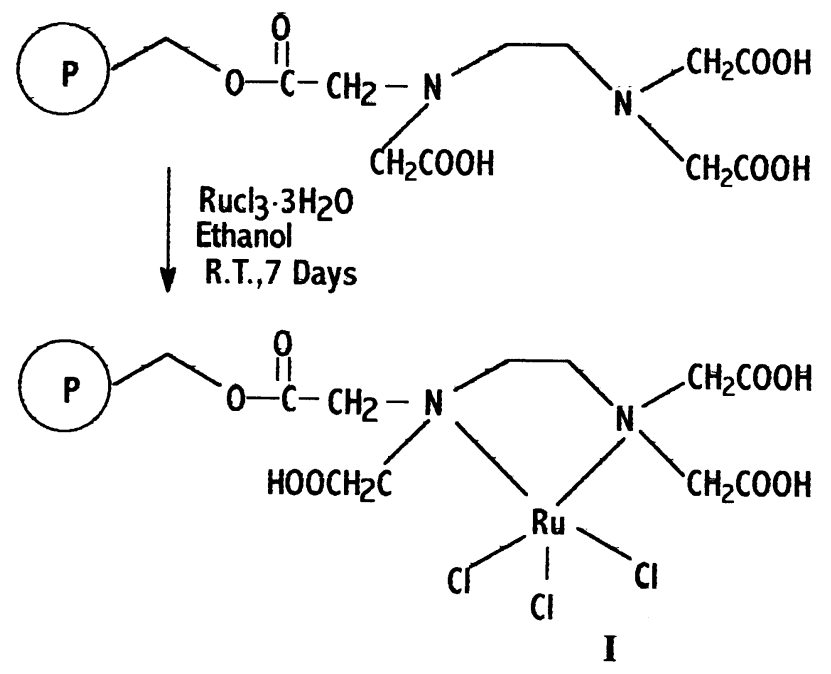

1988). The initial rate was calculated from the slope of the plot of $\mathrm{H}_{2}$ uptake at various time intervals. 1-Hexene was hydrogenated to $n$-hexane and no other side product was found as revealed by GC analysis.

\section{Results and discussion}

\subsection{Characterization of the catalyst}

Physico-chemical properties of the catalyst $\mathrm{H}$ are given in table 1. A decrease in the surface area was observed after loading the metal ions, onto the polymer which might be due to the blocking of the pores of the support as well as due to the steric hinderance. Successful functionalization of the polymer was confirmed by elemental analyses at different stages of preparation of the catalyst (table 1). The nature of the solvent is an important factor that can be varied in order to control the activity and selectivity of polymer-supported catalyst. It is therefore essential to study the swelling behaviour of the catalyst in different solvents. A decrease in swelling was observed as the nature of the solvent was changed from polar to non-polar (table 1). Maximum swelling was observed in water, which might be due to hydrogen bonding of water molecules with amino groups. However, methanol was chosen as a suitable solvent for catalytic reactions because

Table 1. Physico-chemical properties of polymer bound catalyst $\mathrm{H}$.

\begin{tabular}{lcc}
\hline Physical properties & Polymer support & Catalyst \\
\hline Surface area $\left(\mathrm{m}^{2} \mathrm{~g}^{-1}\right)$ & 37.370 & 21.280 \\
Pore volume $\left(\mathrm{cm}^{-1} \mathrm{~g}^{-1}\right)$ & 0.043 & 0.083 \\
$\begin{array}{l}\text { Apparent bulk } \\
\left.\text { density }(\mathrm{g} \mathrm{cm})^{-3}\right)\end{array}$ & - & 0.417 \\
Moisture content (wt\%) & 0.280 & 0.390 \\
& & \\
Elemental analyses* & $\mathrm{C}=68.95$ & $\mathrm{C}=70.42$ \\
& $\mathrm{H}=05.93$ & $\mathrm{H}=06.47$ \\
& $\mathrm{C} 1=17.50$ & $\mathrm{~N}<1$ \\
& & $\mathrm{Ru}=04.95 \times 10^{-4}$ \\
\hline
\end{tabular}

Swelling properties (mol\%)

\begin{tabular}{lcc} 
Solvent & Polymer support & Catalyst \\
\hline Water & 4.03 & $5 \cdot 05$ \\
Methanol & 2.72 & 4.53 \\
Ethanol & 1.98 & $2 \cdot 80$ \\
Dioxan & 1.54 & $2 \cdot 11$ \\
DMF & 1.27 & $2 \cdot 37$ \\
Acetone & $1 \cdot 10$ & $2 \cdot 18$ \\
THF & 1.00 & 1.55 \\
Benzene & 0.68 & 0.92 \\
$n$-hexane & 0.52 & 0.69 \\
\hline
\end{tabular}

*For polymer functionalized with EDTA: $\mathrm{C}=69 \cdot 58, \mathrm{H}=6 \cdot 10$, $\mathrm{N}=1 \cdot 30$ 
of better swelling of the catalyst and miscibility with the substrate. SEM (figure 1) observed a clear change in the morphology of the polymer support after introduction of ligand and metal ions. The UV-visible reflectance spectra showed $d$ - $d$ transitions at $390 \mathrm{~nm}$ which might be due to $\mathrm{Ru}(\mathrm{III})$. The $g_{1}, g_{11}$, and $g_{\text {av }}$ values obtained from ESR (figure 2) were $2 \cdot 26,2.65$ and $2 \cdot 29$, respectively. This is in agreement with a low spin $d^{3}$ centre in a square planar environment; i.e. $\mathrm{Ru}$ is present in a low spin +3 oxidation state. Various FTIR frequencies were assigned as (in $\mathrm{cm}^{-1}$ ) $v(\mathrm{Ru}-\mathrm{Cl})=260, v(\mathrm{Ru}-\mathrm{N})=428, v(\mathrm{C}=\mathrm{O})=1606, v(\mathrm{C}-\mathrm{H})$ $=2913$ as well as the characteristic frequency for $-\mathrm{C}-\mathrm{O}$ in ester at $1261 \mathrm{~cm}^{-1}$ which is much stronger than the other frequencies. This confirms the introduction of ligand through the ester linkage and formation of metal complex on the surface of polymer. TG analysis indicated no change in thermal stability of polymer after complex formation. It showed that catalyst $\mathrm{H}$ is thermally stable up to $150^{\circ} \mathrm{C}$.

\subsection{Kinetics of catalytic hydrogenation}

The kinetics of hydrogenation of 1-hexene with the polymer-bound catalyst $\mathrm{H}$ was investigated. The results are summarized in table 2 . The effect of various parameters on the rate is discussed on the basis of experimental observations.

3.2a Effect of substrate concentration: The effect of concentration of 1-hexene on the rate of hydrogenation was studied at $35^{\circ} \mathrm{C}, 1 \mathrm{~atm}$ pressure and constant catalyst concentration of $0.49 \times 10^{-6} \mathrm{~mol} \mathrm{~L}^{-1}$ of $\mathrm{Ru}(\mathrm{III})$ (table 2). A linear increase in the rate was found with the increase
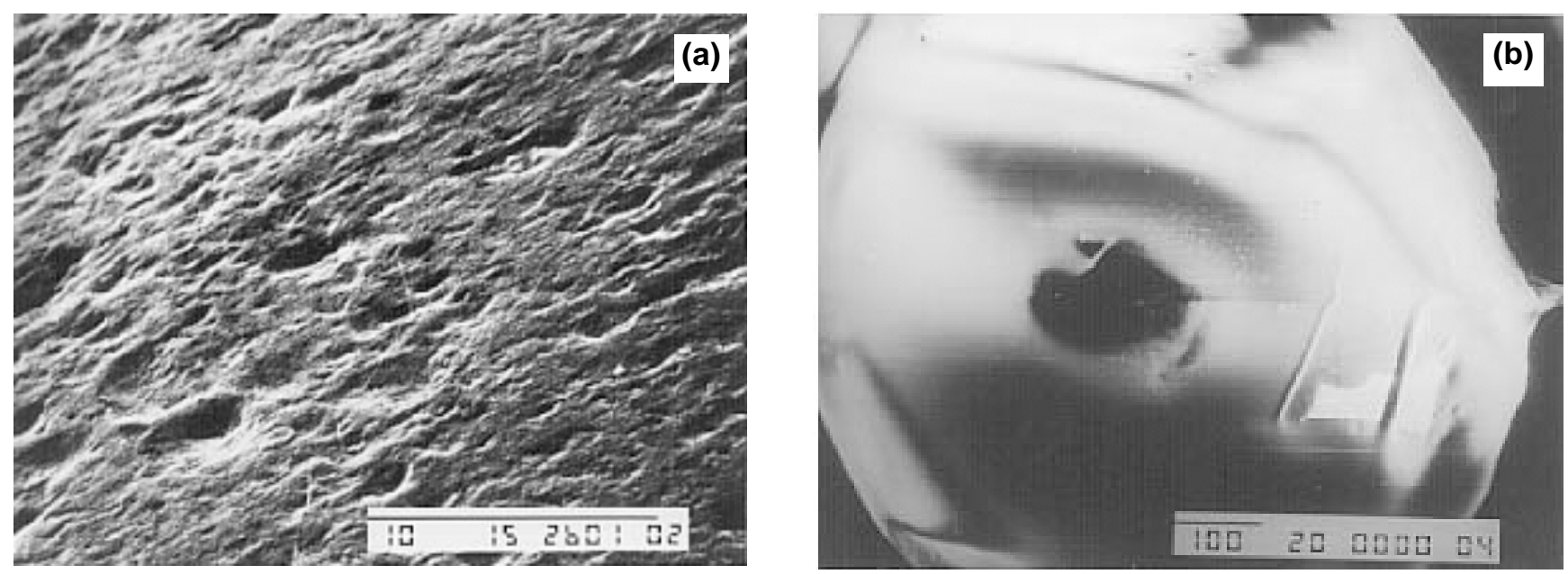

Figure 1. Scanning electron micrographs of (a) polymer support and (b) polymer-bound catalyst.

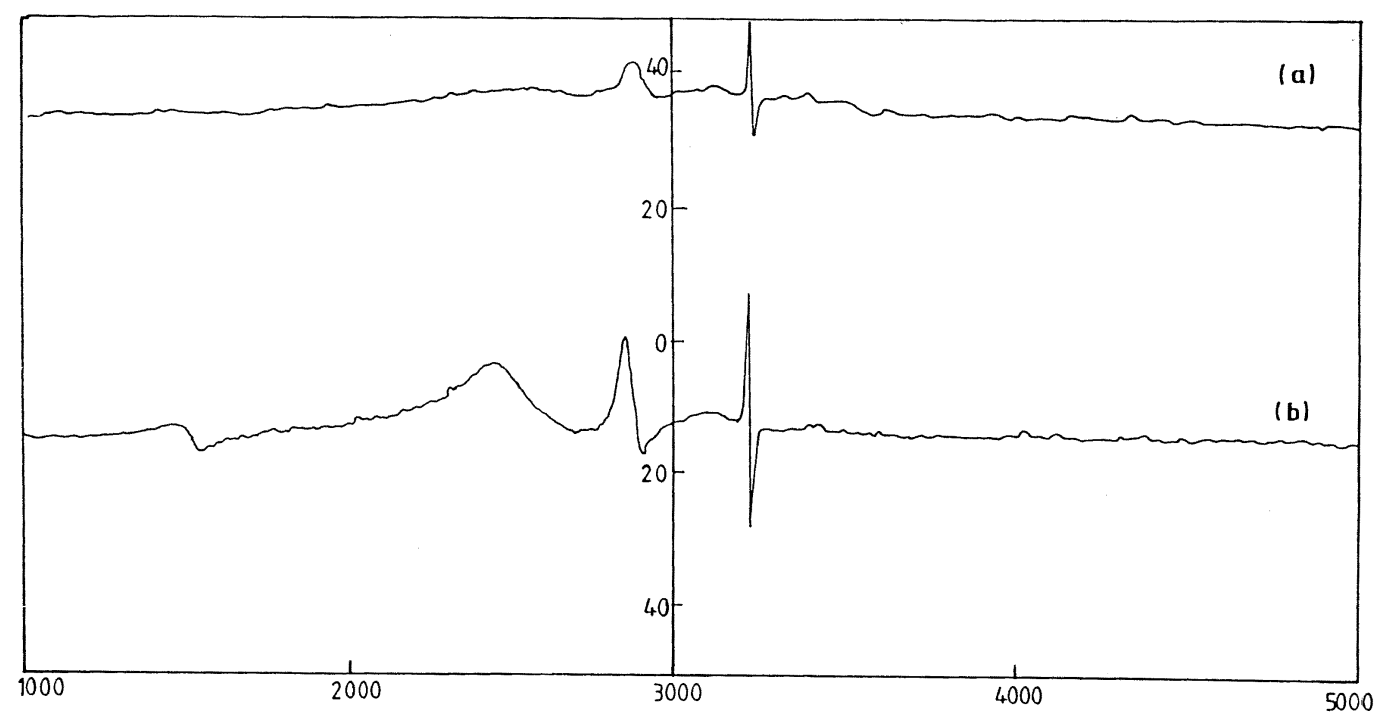

Figure 2. ESR spectra of polymer-bound catalyst (a) at room temperature and (b) at low temperature. 
in substrate concentration. The order of reaction calculated from the slope of the plot of log (initial rate) vs $\log$ [substrate] was found to be unity. The linear plot of $1 /$ rate vs $1 /$ [substrate] (figure 3 ) for supported catalyst indicated that the rate of hydrogenation, $R$, is related to the substrate concentration $[S]$ by the relationship

$$
1 / R=a(1 /[S])+b
$$

where $a$ and $b$ are the slope and intercept of the linear plot.

3.2b Effect of catalyst concentration: The influence of concentration of the catalyst on the rate of hydrogenation of 1-hexene was studied over a range $0.37-0.74 \times 10^{-6}$ mol L $\mathrm{L}^{-1}$ of $\mathrm{Ru}(\mathrm{III})$ at $35^{\circ} \mathrm{C}, 1 \mathrm{~atm}$ pressure and at a fixed substrate concentration. The results are summarized in table 2 . The rate increases linearly with respect to catalyst concentration in all cases indicating that the mass-transfer effect could be neglected under the reaction conditions (Terasawa et al 1978). This also effectively rules out any possibility of dimerization of catalyst in the range studied (Dalal et al 1999). The order of reaction calculated from the slope of the linear plots of $\log$ (initial rate) vs $\log$ [catalyst] were found to be unity, indicating availability of all the active sites for the catalytic reaction.

3.2c Effect of temperature: Catalytic reactions were studied over a range of $25-40^{\circ} \mathrm{C}$, at a fixed catalyst concentration of $0.49 \times 10^{-6} \mathrm{~mol} \mathrm{~L}^{-1}$ of $\mathrm{Ru}(\mathrm{III})$ at atmospheric pressure. The concentration of substrate was also kept constant. The results are given in table 2. The energy of activation calculated from Arrhenius plot (figure 4)

Table 2. Summary of the kinetics of hydrogenation of 1-hexene by catalyst $\mathrm{H}$ at 1 atmospheric pressure using $20 \mathrm{ml}$ solvent.

\begin{tabular}{|c|c|c|c|c|}
\hline $\begin{array}{l}{[\mathrm{Ru}(\mathrm{III})]} \\
\left(\mathrm{mol} \mathrm{L}^{-1}\right) 10^{6}\end{array}$ & $\begin{array}{c}{[1 \text {-hexene] }} \\
\left(\mathrm{mol} \mathrm{L}^{-1}\right) 10^{3}\end{array}$ & $\begin{array}{c}\text { Temperature } \\
\left({ }^{\circ} \mathrm{C}\right)\end{array}$ & Solvent & $\begin{array}{c}\text { Rate of } \\
\text { reaction } \\
\left(\mathrm{ml} \mathrm{min}^{-1}\right)\end{array}$ \\
\hline \multirow[t]{4}{*}{0.49} & $4 \cdot 00$ & 35 & Methanol & $0 \cdot 23$ \\
\hline & $6 \cdot 00$ & & & $0 \cdot 29$ \\
\hline & 8.00 & & & 0.54 \\
\hline & $10 \cdot 00$ & & & 0.68 \\
\hline $0 \cdot 37$ & $8 \cdot 00$ & & & $0 \cdot 32$ \\
\hline 0.49 & & & & $0 \cdot 54$ \\
\hline 0.62 & & & & 0.72 \\
\hline 0.74 & & & & 0.95 \\
\hline \multirow[t]{4}{*}{0.49} & $8 \cdot 00$ & 25 & & $0 \cdot 25$ \\
\hline & & 30 & & $0 \cdot 35$ \\
\hline & & 35 & & $0 \cdot 54$ \\
\hline & & 40 & & $0 \cdot 86$ \\
\hline \multirow[t]{4}{*}{0.49} & 8.00 & 35 & Methanol & $0 \cdot 54$ \\
\hline & & & Ethanol & $0 \cdot 48$ \\
\hline & & & THF & $0 \cdot 32$ \\
\hline & & & Benzene & $0 \cdot 15$ \\
\hline
\end{tabular}

was found to be $70 \cdot 8 \mathrm{~kJ} \mathrm{~mol}^{-1}$. The lower energy of activation is indicative of the fast reaction. The entropy of activation calculated from the rate data was found to be $-10 \cdot 4 \mathrm{eu}$.

3.2d Influence of nature of solvent: The kinetics of hydrogenation of 1-hexene was studied using various solvents at $35^{\circ} \mathrm{C}$ and $1 \mathrm{~atm} \mathrm{H}_{2}$ pressure (table 2). A decrease in the rate was found as the nature of the solvent was changed from polar to non-polar. The higher rate of reaction in polar solvents might be due to better swelling of the polymers and hence the availability of the catalytic sites.

\subsection{Study of life cycle of catalyst}

The stability of fresh as well as used (used for reaction and filtered out) polymer-bound catalyst under repeated catalytic cycles was tested. The experiment was carried out at $35^{\circ} \mathrm{C}$ and 1 atm $\mathrm{H}_{2}$ pressure for $5 \mathrm{~h}$ by injecting

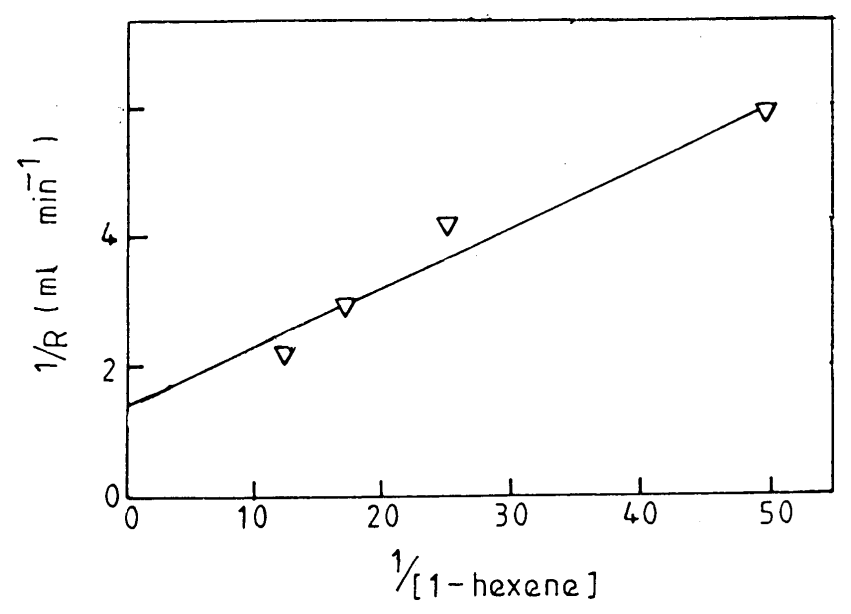

Figure 3. Plot of $1 /$ rate vs $1 /$ [substrate].

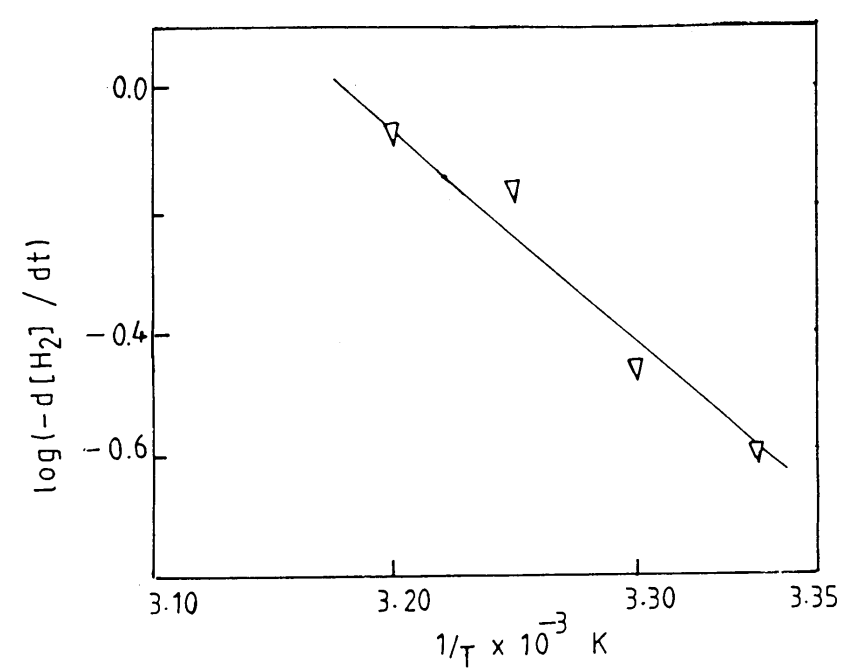

Figure 4. Arrhenius plot for hydrogenation of 1-hexene using polymer-bound catalyst. 
Table 3. Life cycle study of catalyst $\mathrm{H}$ at $35^{\circ} \mathrm{C}$ and $1 \mathrm{~atm}$ pressure using $20 \mathrm{ml} \mathrm{methanol}{ }^{\dagger}$.

\begin{tabular}{lc}
\hline Time (min) & Rate $\left(\mathrm{ml} \mathrm{min}^{-1}\right)$ \\
\hline 45 & $0.54(0.54)$ \\
90 & $0.54(0.54)$ \\
165 & $0.52(0.50)$ \\
210 & $0.49(0.45)$ \\
265 & $0.44(0.39)$ \\
\hline${ }^{\dagger}[\mathrm{Ru}(\mathrm{III})]=0.49 \times 10^{-6} \mathrm{~mol}^{-1}$ \\
{$[1$-hexene $]=8.00 \times 10^{-3} \mathrm{~mol}^{-1}$} \\
for every injection. \\
Values for the used catalyst are \\
indicated in parenthesis.
\end{tabular}

$20 \mu \mathrm{L}$ substrate at $45 \mathrm{~min}$ intervals. The rate of reaction was measured as a function of time. No change in the rate of reaction was observed up to two cycles (table 3). Thereafter, the rate of reaction decreased slowly. This might be due to leaching of the metal ions from the surface of the polymer, which was confirmed by estimating the metal content after completion of the experiment. A loss of $33 \%$ of the metal from the support was observed after five cycles.

\section{Reaction mechanism}

The reaction mechanism for hydrogenation with $\mathrm{H}_{2}$ by metal ions/complexes in homogeneous medium and heterogenized medium has been studied widely (Terasawa et al 1978; Kaneda and Imanaka 1991). On the basis of literature evidence, a probable reaction mechanism may be suggested.

$$
\begin{aligned}
& L \mathrm{Ru}(\mathrm{III}) \text { complex }+\mathrm{H}_{2} \stackrel{K}{\leftrightarrows} L H \mathrm{Ru}(\mathrm{III}) \text { complex, } \\
& L H R u(I I I) \text { complex }+S \underset{k_{-1}}{\stackrel{k_{1}}{\leftrightarrows}} L H S R u(I I I) \text { complex } \\
& L H S R u(I I I) \text { complex }+\mathrm{H}_{2} \stackrel{k_{2}}{\rightarrow} L H R u(\text { III) complex } \\
& +n \text {-hexane, }
\end{aligned}
$$

where $K$ is the equilibrium constant, $L$ the polymeric ligand and $S$ the substrate. On the basis of step 3, which is a rate determining step, the rate law can be expressed as:

$$
\text { Rate }(R)=\frac{K k_{1} k_{2}[S]\left[H_{2}\right][C]}{k_{1}+k_{2}\left[H_{2}\right]},
$$

where $S$ is substrate and $C$ the catalyst.

\section{Conclusion}

Ruthenium(III)-EDTA complex was successfully heterogenized using commercially available $8 \%$ cross-linked styrene-divinylbenzene copolymer. The anchoring of metal complex on the surface of the polymer was confirmed by elemental analyses, FTIR, UV-vis, ESR and SEM. This catalyst was found to be effective for hydrogenation of 1-hexene. Catalyst was found to be stable up to two cycles after which leaching of metal occurred, decreasing activity.

\section{Acknowledgements}

Thanks are due to Prof. A K Rakshit, Head, Department of Chemistry, for providing facilities and R\&D centre, IPCL, Baroda for characterizing the catalyst. Financial support from CSIR, New Delhi, is gratefully acknowledged.

\section{References}

Augustine R L 1997 Catal. Today 37419

Dalal M K and Ram R N 1997 Eur. Polym. J. 331495

Dalal M K, Gokak D T, Patel D R and Ram R N 1998 Indian J. Chem. Tech. 5376

Dalal M K, Upadhyay M J and Ram R N 1999 J. Mol. Catal. A: Chemical 142325

Gokak D T, Kamath B V and Ram R N 1988 J. Appl. Polym. Sci. 351523

Hartley F R (ed.) 1985 Supported metal complexes (Dordrecht: Reidel)

Iwasawa Y (ed.) 1985 Tailored metal catalysts (Dordrecht: Reidel)

John J, Dalal M K, Patel D R and Ram R N 1997 J. Macromol. Sci. Pure Appl. Chem. A34 489

John J, Dalal M K and Ram R N 1999 J. Mol. Catal. A: Chemical $\mathbf{1 3 7} 183$

Kaneda K and Imanaka T 1991 Trends Org. Chem. 2109

Schlick S, Bortel E and Dyrek K 1996 Acta Polym. 471

Singh A K, Katyal M and Singh R P 1976 J. Indian Chem. Soc. 53691

Teraswawa M, Kaneda K, Imanaka T and Teranishi S $1978 \mathrm{~J}$. Catal. 51406 